\title{
Measure on Eco-Efficiency of Thai Growing-Fishing Pig Farms
}

\author{
C. Rattanapan, T. T. Suksaroj, S. Wongsawass, and W. Ounsaneha
}

\begin{abstract}
This research measured the eco-efficiency of Thai growing-fishing pig farms. Eco-efficiency indicators were developed by the previous literatures and field observation contributed for the investigation of the potential environmental impact in a material flow analysis. Eco-Eco-efficiency degrees and trends at economic and environment performances for Thai growing-fishing pig farms during 2010-2012 was calculated. The eco-efficiency degrees and trends were assessed by World Business Council for Sustainable Development recommendation and Snapshot graph plot, respectively. The results showed that the highest and lowest eco-efficiency degrees of Thai growing-fishing pig farms were drug and energy consumptions, respectively. The eco-efficiency of Thai growing-fishing pig farms snapshot showed that most eco-efficiency indicators were located in Fully-Eco-Efficiency.

However, only wastewater production indicator was located in Haft-eco-efficiency because the growing-fishing pig farm required the water for cleaning twice a day. Biogas production from the growing-fishing pig farms wastewater should be recommended for enhancing approach of eco-efficiency performance.
\end{abstract}

Index Terms-Eco-efficiency, growing-fishing pig, farm, sustainable development, Thailand.

\section{INTRODUCTION}

Animal production of Thailand, especially commercial pig production, showed the rapidly increasing trends from household to large commercial scale, which also means transfers in animal production management such as feeding, housing, technology, etc [1], [2]. This trend enhanced the chance of air, water and soil pollutions [3], [4]. Specifically, the growing pig period is commonly known for its ability to over a wide range of dietary energy concentrations to maintain a constant daily energy intake [5]. The feeding or growing stage accounted for the largest use of natural resources in pork production [6]. This period of pig production required more resources and energy per day. From the report from office of Agriculture Economics of Thailand [7] found that sixty-three percent of pig production in Thailand was growing-fishing pig. Therefore, much pollution was discharged to the environment by growing-fishing pig farms.

Sustainable development can be probable as a continuous

Manuscript received April 20, 2013; revised June 8, 2013. This work was supported The Thailand Research Fund (contract reference number RDG55520075) and Knowledge Network Institute of Thailand.

C. Rattanpan and S. Wongsawass are with ASEAN Institute for Health Development, Mahidol University, Salaya, Phutthamonthon, Nakhonpathom, 73710, Thailand (e-mail: cheerawitrat@mahidol.ac.th, cheerawit@hotmail.com).

T. T. Suksaroj and W. Onsaneha are with Faculty of Environmental Management, Prince of Songkla University, Hat Yai, Songkhla, 90112, Thailand. social process, which merges a strategy and questions of ethics and provides time for necessary technological transformation [8]. Sustainable development must consider economic, environmental and social considerations, simultaneously [9]. Eco-efficiency has been extensively favored as a method of evaluating the balance between economic performance and environmental performances by the World Business Council of Sustainable Development in the early 1990s [10], [11]. The term of eco-efficiency concept is basically assessed by ratios according to economic value of the goods and services produced to the environmental pressure and impacts involved in production processes [12]. Besides, various international organizations have recognized that eco-efficiency assessment is a strong instrument of providing managers and policy makers to support them design better managerial strategies and environmental policies with achieving sustainable development [13]. Moreover, many researches [14]-[18] motioned that eco-efficiency concept can be applied for strengthening agriculture performance.

In this context, the objective of this paper was to measure the degree and trend eco-efficiency of growing-fishing pig farms in Thailand during the period of 2010-2012. In a first stage, eco-efficiency indicators of growing-fishing pig farms in Thailand were developed by material flow analysis proposed by Rattanapan et al. [19]. Secondly, the convergence eco-efficiency in making use of the methodological approach proposed by WBSCD [11] was applied to measure the degree Thai growing-fishing pig farms. Finally, eco-efficiency trend of Thai growing-fishing pig farms based on snapshot graph plot [20] was determined.

\section{MATERIAL AND MethoD}

\section{A. Eco-Efficiency Indicator and Questionnaire}

Eco-efficiency is the more with less activity, or economic output production with minimal natural resources and environmental impact [21]. The ratio between the value product and the environmental impacts of the product or service is measured as the eco-efficiency [11], [22]. It can be quantified through indicators based on the ratio of economy and environment [20]. Then, specific indicator development for each organization is also needed to evaluate the eco-efficiency performance [19]. Therefore, eco-efficiency indicator of Thai growing-fishing pig farms was developed in the first step of this study by material flow analysis proposed by Rattanapan et al. [19] and verified by filed site observation in a growing-fishing pig farm, Ratchaburi province, Thailand. Moreover, eco-efficiency indicator was benchmarked by general economic and environmental indicator of WBCSD. Next, the selected eco-efficiency indicator of Thai 
growing-fishing pig farms was developed for a collecting data questionnaire based on the standard questionnaire from National Round Table on the Environment and the Economic [20]. This questionnaire was approved by the ethics committee of Mahidol University Institutional Review Board.

\section{B. Data Collection}

All the data collected and determined for this assessment were recluse from questionnaires completed based on direct interviews with growing-fishing pig farm owners. The economic and environmental performance during the years 2010-2012 of growing-fishing pig productions was collected from four farms throughout Thailand. The collecting data was structured in a three-step process based on questionnaire parts. Firstly, socio-demographic of farm owner about organization and finance, number and species of growing-fishing pig, production situation were asked. Secondly, environmental performance of each growing-fishing pig process was conducted. Finally, economic performance of growing-fishing pig farms was collected. However, the data obtained in all step were compared to literature review for identifying inconsistent values. Even most of the farm data and the literature data were in accordance, values far outside the regional average were double checked by means of further investigations directly on the farms.

\section{Eco-Efficiency Assessment}

Eco-efficiency assessment can be defined in different method. For this study, the assessment considers the ratio between the economic value and the environmental impact of the material of analysis [11].The eco-efficiency assessment was taken from the WBCSD approach and previous literature [23] follows in equation (1):

$$
E E_{n}=\frac{E I_{n}}{\sum E_{n m}}
$$

where, $E_{I n}$ and $E N_{n m}$ are the economic and environmental indicators, respectively in US dollar. The environmental indicator is environmental impacts of growing-fishing pig farm. The snapshot graph proposed by the Anite System in Netherland [20] was adopted for eco-efficiency assessment in this study. The percent variations of the economic and environmental indicators were analyzed following in equation (2):

$$
\% V E=\frac{\left(\sum E_{i}-\sum E_{b}\right) \times 100}{\sum E V_{b}}
$$

where $\% V E=$ Percent variation of economic or environmental indicators, $\sum E_{i}=$ Summation of economic or environmental indicators of growing-fishing pig farm, and $\sum E_{b}=$ Summation of economic or environmental indicators of growing-fishing pig farm. The percent variation analysis of economic and environmental indicators of growing-fishing pig farm were subsequently plotted in one graph, where the $\mathrm{Y}$-axis and $\mathrm{X}$-axis are the variation of the percent variation of the economic indicator and environmental indicator of growing-fishing pig farms, respectively. The interpretation of the eco-efficiency level is made by the X-Y plan [24].

\section{RESULTS AND DISCUSSION}

\section{A. Delineation of Growing-Fishing Pig Farm}

Stages of growing-fishing pig farm are shown in Fig. 1 Material flow analysis of growing-fishing pig farm was generated by the literature review and benchmarked by farm observation in a growing-fishing pig farm, Ratchaburi province, Thailand. The important production required for growing-fishing pig farm was the piglet. The production chain consisted of various stages on growing-fishing pig farm including up-stream stage, on-farm stage, and stage after farm gate. Up-stream stages implicated to farm input to next stage. During storage, growing-fishing was supplemented about more than one hundred and twenty days for one hundred and twenty kilograms of growing-fishing pig. This result was higher efficiency than Vietnamese pig production, which reach about $105 \mathrm{~kg}$ at 174 days [25]. Stages after farm gate are size selection and retail. During cultivation of feed, output of growing-fishing pig farm was occurred. The environmental impact of stages was allocated to outputs using material flow analysis. In this study, the main output of this study was the wastewater because the water was used for cleaning stall of growing-fishing pig farm.

\section{B. Eco-Efficiency Indicator of Growing-Fishing Pig Farm}

Currently, eco-efficiency indicators remain fully used and have been adopted by many countries as an important tool for resource management [22]. In this paper, material flow analysis was applied to develop the indicator of eco-efficiency for growing-fishing pig farm. Material flow analysis was claimed by various researches [26]-[28] that it is the proficient instrument for assessing the eco-efficiency. Moreover, eco-efficiency indicator of growing-fishing pig farm was modified by the principle indicators of eco-efficiency from WBCSD [11]. Thus, eco-efficiency indicators of growing-fishing pig farm are shown in Table 1. The economic indicator of growing-fishing pig farm is net sale. The environmental indicators of growing-fishing pig farm are feed consumption, drug consumption, energy consumption, water consumption, and waste production. Then, the collecting data questionnaire of growing-fishing pig farms was taken from the standard questionnaire from National Round Table on the Environment and the Economic [20] and approved by the ethics committee of Mahidol University Institutional Review Board.

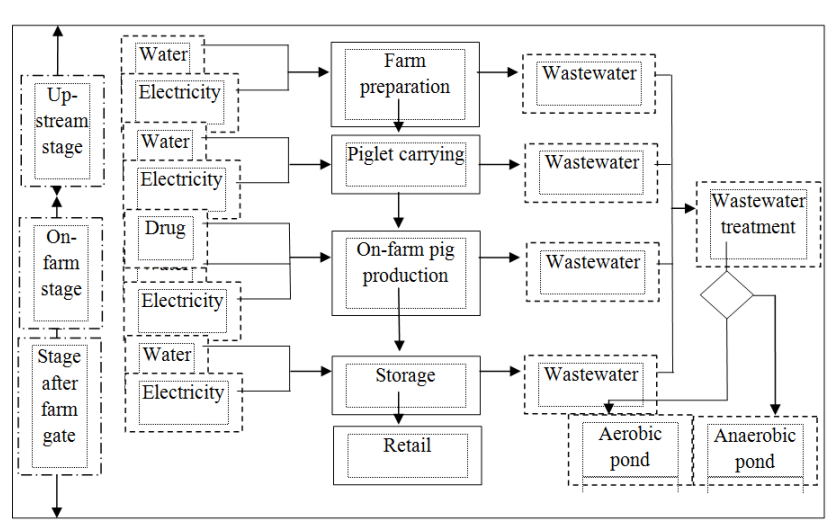

Fig. 1. Delineation of growing-fishing pig farm 
TABLE I: ECO-EFFICIENCY INDICATORS OF GROWING-FISHING PIG FARM

\begin{tabular}{ccc}
\hline Indicators & Unit & Measuring method \\
\hline Net sales & USD & $\begin{array}{c}\text { General accepted accounting } \\
\text { principles }\end{array}$ \\
Feed consumption & $\mathrm{kg}$ & Quantity use for conversion \\
Drug consumption & tube & Quantity use for conversion \\
Energy consumption & $\mathrm{MJ}$ & Quantity use for conversion \\
Water consumption & $\mathrm{m}^{3}$ & Quantity use for conversion \\
Wastewater production & $\mathrm{kg}$ & Quantity production \\
& & for conversion \\
\hline
\end{tabular}

\section{Eco-Efficiency Degree of Growing-Fishing Pig Farm}

This section presented and discussed of eco-efficiency assessment. Degrees of eco-efficiency represented the ability reduction of all environmental impacts while retaining value added have been analyzed [15] for averaging four growing-fishing pig farms. Eco-efficiency degree of growing-fishing pig farm has been calculated according to expression (1). The results are shown in Fig. 2. It indicated that net sale value for averaging four growing-fishing pig farms was 14399 USD and was lowest at 2010 due to flooding during this year. Drug consumption of growing-fishing pig farm was highest degree of eco-efficiency because the supply of drugs, vaccines and medicines is also important cause of concern in the livestock industry [29]. Moreover, the results investigated that energy consumption of growing-fishing pig farm was the lowest degrees of eco-efficiency because the energy consumption of growing-fishing pig farms required only electricity for supplying ventilation vans and water pumps. However, the eco-efficiency degree of energy consumption for growing-fishing pig farm has shown an upward trend every year. Therefore, the growing-fishing pig farms should be developed the reduction method of energy consumption for decreasing the operation cost and supporting sustainable development.

\section{Eco-Efficiency Trend of Thai Growing-Fishing Pig}

\section{Farm}

Eco-efficiency trends of growing-fishing pig farms have been calculated based on equation (2) and plotted by Snapshot graph, which was modified by the Anite System in Netherland [20].The result is shown in Fig. 3. It indicated that most eco-efficiency indicators of growing-fishing pig farm located in Fully-eco-efficiency and showed the nice trends, which is the increasing of economic indicator and the reduction of environmental indicator [24]. However, only wastewater production indicator was located in Haft-eco-efficiency, which was the increasing chance of economic or environment, because the growing-fishing pig was cleaned twice a day. Large volumes of wastewater were generated by flushing the pigs and washing solid manure. It was measured that about $40 \mathrm{~L}$ of water were used per pig per day [25]. Hence, the reduction approach of growing-fishing pig farms should be developed. Vu et al [25] recommended that biogas production of wastewater is practiced on a high proportion of growing-fishing pig farms systems efficiently. Therefore, the result of this study can be confirmed that eco-efficiency concept was effective in improving growing-fishing pig farms based on the balance between economic and environmental issue.
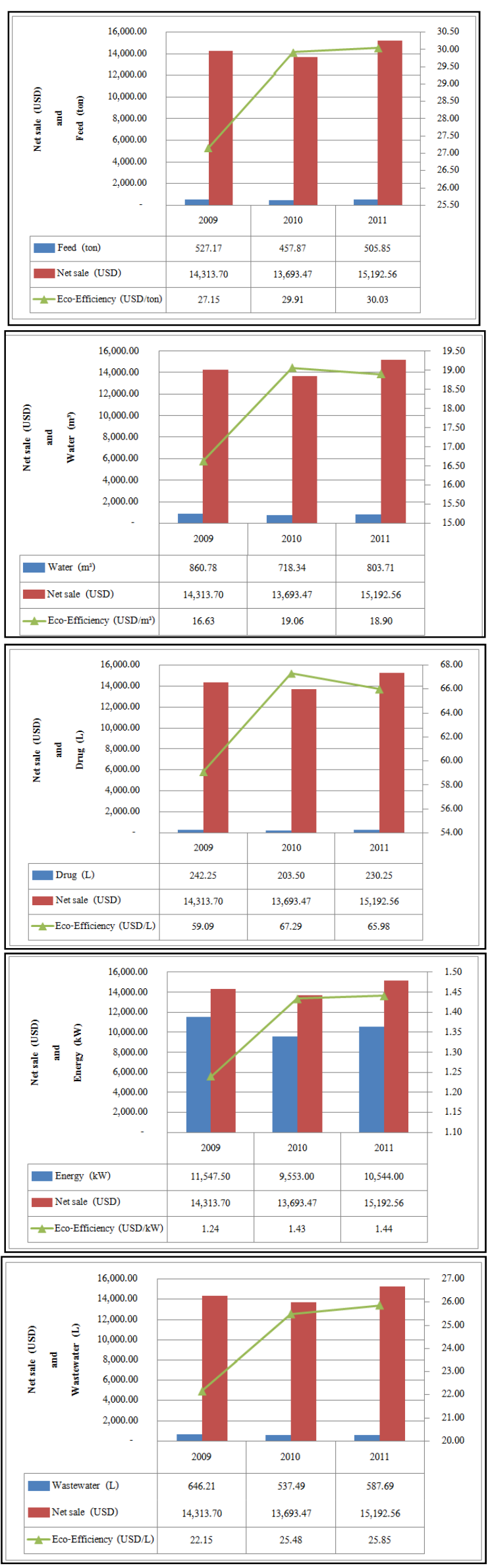

Fig. 2. Eco-efficiency degree of Thai growing-fishing pig farm 


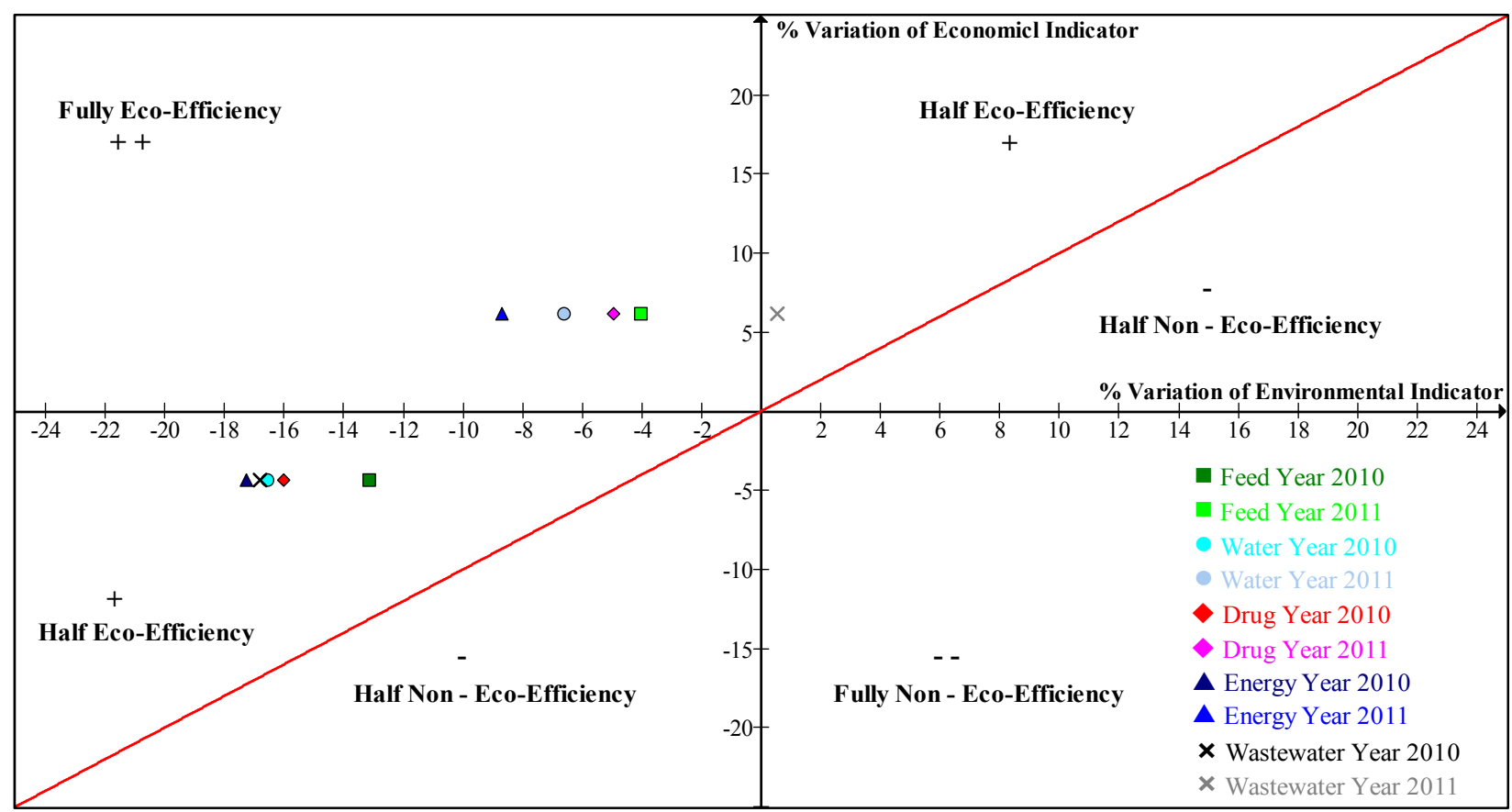

Fig. 3. Eco-efficiency trend of Thai growing-fishing pig farms.

\section{CONCLUSION}

Application of eco-efficiency as assessment technique for measuring the performance of Thai growing-fishing pig farms was studied. Eco-efficiency degrees of Thai growing-fishing pig farms were determined according to the recommendation from World Business Council for Sustainable Development. The result showed that the drug and energy consumptions were the highest and lowest eco-efficiency degrees of Thai growing-fishing pig farms, respectively. Then, Snapshot graph was plotted for evaluating eco-efficiency trends of growing-fishing pig farms. The result indicated that only wastewater production indicator was located in Haft-eco-efficiency.

Therefore, the utilization of growing-fishing pig farms wastewater for biogas production should be recommended.

\section{ACKNOWLEDGMENT}

This research was supported by The Thailand Research Fund (contract reference number RDG55520075) and Knowledge Network Institute of Thailand.

\section{REFERENCES}

[1] S. Krainara, "The increasing production of pig farms in Lamtap District, Karbi province," M.S. thesis, Marketing Major, Phuket Rajabhhut University, 2007.

[2] N. Paraksa et al., "Study of the contract farming for livestock production (swine) in Thailand," Final report for Thailand Research Fund, Bangkok, 2008.

[3] B. X. An, T. R. Preston, and F. Dolberg, "The introduction of low cost polyethylene tube biodigesters on small scale farms in Vietnam," Livestock Research for Rural Development, vol. 9, pp 1-6, 1997.

[4] P. Gerber, P. Chilonda, G. Franceschini, and H. Menzi, "Geographical determinants and environmental implications of livestock production intensification in Asia," Bioresource Technology, vol. 96, pp. 263-276, 2005.

[5] D. J. A Cole, J. E. Duckworth, and W. Holmes, "Factors affecting voluntary feed intake in pigs. The effect of digestible energy content of the diet on the intake of castrated male pigs housed in holding pens and in metabolism crates," Animal Production, vol. 9, pp. 141-148, 1967.
[6] J. K. Grubbs et al., "Selection for residual feed intake alters the mitochondria protein profile in pigs," Journal of Protemics, vol. 80, pp. 334-345, 2013.

[7] Office of Agriculture Economics of Thailand. (2012). Situation and trend of important agriculture production in 2012. [Online]. Available: http://www.oae.go.th/download/journal/trends2555. pdf.

[8] O. Sergienko, "Learning of eco-efficiency tools through university -cooperate cooperation," Addressing Global Environmental, pp. 43-50, 2009.

[9] S. Cowell and S. Parkinson, "Localisation of UK food production: An analysis using land area and and energy as indicators," Agriculture, Ecosystems and Environment, vol. 24, pp. 221-236, 2003.

[10] S. Schmidheiny, "Changing course - a global business perspective on development and the environment," World Business Council for Sustainable Development (WBCSD), pp.25-30, 1992.

[11] World Business Council for Sustainable Development (WBCSD), "The world business council for sustainable development eco-efficiency: Creating more value with less impact", 2000.

[12] S. Schmidheiny and J. L. Zorraquin, Financing change, the financial community, eco-efficiency and sustainable development, MIT Press, Cambridge, 1996.

[13] United Nations, "Eco-efficiency indicators: measuring resource use efficiency and the impact of economic activities on the environment," Greening of Economic Growth Series, ST/ESCAP/ 2561, pp. 102-105, 2009.

[14] R. J. Wilkins, "Eco-efficient approaches to land management: a case for increased integration of crop and animal production systems," Philosophical Transactions, vol. 363, pp. 517-525, 2008.

[15] A. J. Picazo-Tadeo, J. A. Gómez-Limón, and Reig-Martínez, "Assessing farming eco-efficiency: A Data Envelopment Analysis approach," Journal of Environmental Management, vol. 92, pp. 1154-1164, 2011.

[16] D. Iribarren et al., "Benchmarking environmental and operational parameters through eco-efficiency criteria for dairy farms," Science of the Total Environment, vol. 409, pp. 1786-1798, 2011.

[17] J. Gomez-Limon, A. Picazo-Tadeob, and E. Reig-Martinezb, "Eco-efficiency assessment of olive farms in Andalusia," Land Use Policy, vol. 29, pp. 395- 406, 2012.

[18] T. E. Ewoukem et al., "Environmental impacts of farms integrating aquaculture and agriculture in Cameroon," Journal of Cleaner Production, vol. 28, pp. 208-214, 2012.

[19] C. Rattanapan, T. T. Suksaroj, and W. Ounsaneha, "Development of eco-efficiency indicators for rubber glove product by material flow analysis," Procedia - Social and Behavioral Sciences, vol. 40, pp. 99-106, 2012.

[20] National Round Table on the Environment and the Economy (NRTEE), "Calculating eco-efficiency indicator: A workbook for industry", Canada, 2000. 
[21] T. Kuosmanen and M. Kortelainen, "Measuring eco-efficiency of production with data envelopment analysis," Journal of Industrial Ecology, vol. 9, no. 4, pp. 59-72, 2005.

[22] Y. Yu, D. Chena, B. Zhua, and S. Hua, "Eco-efficiency trends in China, 1978-2010: Decoupling environmental pressure from economic growth," Ecological Indicators, pp. 177-184, 2013.

[23] W. Ounsaneha, T. T. Suksaroj, and K. Chamondusit, "Selection of the sustainable area for rubber plantation of Thailand by Eco-efficiency," Procedia - Social and Behavioral Sciences, vol. 40, pp. 58-64, 2012.

[24] K. Charmondusit and K. Keartpakpraek, "Eco-efficiency evaluation of the petroleum and petrochemical group in the map Ta Phut Industrial Estate, Thailand," Journal of Cleaner Production, vol. 19, pp. 241-252, 2011.

[25] T. K. V. Vu, M. T. Tran, and T. T. S. Dang, "A survey of manure management on pig farms in Northern Vietnam," Livestock Science, vol. 112, pp. 288-297, 2007

[26] C. Zhao, D. M. Wang, and Z. X. Zhang, "Analysis of material flow and energy flow in forest logging system," Journal of Nanjing Forestry University (Natural Sciences Edition), vol. 32, pp. 37-40, 2008.

[27] L. Lauwers, "Justifying the incorporation of the materials balance principle into frontier based eco-efficiency models," Ecological Economic, vol. 68, pp. 1605-1614, 2009.
[28] Y. Zhao and C. Zhao, "Eco-efficiency evaluation indicator of plantation harvesting system and its improvement based on material flow analysis", Asia-Pacific Power and Energy Engineering Conference, APPEEC 2011, Proceedings of Art, no. 5748784, pp.1-4, 2011.

[29] J Mutambara, "A preliminary review of regulatory constraints affecting pig industry in Zimbabwe," Livestock Research for Rural Development, vol. 25, no. 3, pp.205-208, 2013.

Cheerawit Rattapan was appointed to the Lecture of ASEAN Institute for Health Development, Mahidol University, Thailand in October, 2009 after completing a Doctoral Degree in Biotechnology at Prince of Songkla University, Thailand. He has over 4 years of experience research environmental fields. He has published more than 15 technical papers in peer refereed journal and proceeding with a strong citation record. He has been a reviewer of several international journals in environmental areas. His current research interests focus on environmental biotechnology, environmental and occupational health, environmental management and sustainable development. 